\title{
Experimental investigation on a centrifugal compressor by means of rectangular, elliptical and sloping squealer tips
}

\author{
S. Senthil ${ }^{1}$ and N. Krishna Mohan ${ }^{2}$ \\ ${ }^{1}$ Dept. of Mechanical Engineering, Mailam Engineering College, Villupuram-604 304, TamilNadu, India. \\ ${ }^{2}$ Dept. of Mechanical Engineering, Annamalai University, Chidambaram-608 002, Tamil Nadu, India \\ senthil_iit@yahoo.com
}

\begin{abstract}
The objective of the present investigation is to explore the possibility of using different types of squealers to improve the performance of centrifugal compressor. The following experiments are carried out to achieve the objectives: measurement of performance of the compressor with rectangular squealers, elliptical squealers and sloping squealers, impeller exit traverse with a pre-calibrated five hole probe for all configuration at three coefficients, viz $\phi=0.28$ (near design), $\phi=0.34$ (above design) and $\phi=0.18$ (below design) and static pressure distribution on the shroud over the impeller at the above three flow coefficient. From the present investigation, it is concluded that sloping type squealer tip has beneficial effects in increasing energy co-efficient and efficiency of the compressor.
\end{abstract}

Keywords: Centrifugal compressor, spacers, squealers, tip clearance, performance characteristics. Introduction

The flow field in an impeller passage of a centrifugal compressor is highly complex, three-dimensional and unsteady. A designer for a centrifugal compressor should have complete understanding on the influencing parameters, there by one can design for better performance and efficiency. The performance of a compressor is inherently deteriorated by different loses that occur at different sections of the compressor stage. They are as follows: shock loss at an inducer inlet, wall friction loss within impeller channels, tip leakage loss, secondary flow losses, mixing loss at diffuser inlet, wall friction loss within a diffuser, sudden expansion loss at a scroll inlet, wall friction loss within a scroll.

Pampreen (1973) concluded that clearance effects have pronounced influence on the performance of centrifugal and axial compressors compared to Reynolds number effects. Ishida and Senoo (1981) used two entirely different types of centrifugal blowers one with a radial blade impeller and the other with a backward blade impeller, measured the pressure distribution along the shroud at five flow coefficient and seven tip clearances. Senoo and Ishida (1987) observed the deterioration of compressor performance due to tip clearance of centrifugal impeller. They modified their theory on the tip clearance loss of centrifugal impeller to include the variation of slip co-efficient of the impeller due to the tip clearance, by deriving a rational relationship between two empirical parameters in the theory. They have compared experimental data in the literature with prediction, to select corresponding flow rates of a compressor with different values of tip clearance loss.
Heyes et al. (1992) observed the effect of blade tip geometry on the tip leakage flow in axial turbine cascades. The investigation includes an examination of the performance of the cascades with a variety of tip geometries. The effects of using plain tips, suction side squealers, and pressure side squealers are reported. Ameri et al. (1998) observed the effect of squealer tip on rotor heat transfer and efficiency. Experimental investigations are performed to measure the detailed heat transfer coefficient and static pressure distribution on the squealer tip of a gas turbine blade in the five-blade stationary linear cascade. Results show that the heat transfer coefficient on the cavity surface and rim increases with an increase in tip clearance. The heat transfer coefficient on the rim is higher than the cavity surface. The cavity surface has a higher heat transfer coefficient near the leading edge region than the trailing edge region. The squealer tip blade provides a lower overall heat transfer coefficient when compared to the flat tip blade. Azad et al. (2000) compared the heat transfer and flow on the squealer tip of a gas turbine blade with that on a flat tip. Shridhara (2001) conducted tests with partial shrouds, with out partial shrouds and turbulence generator on centrifugal compressor with different values of tip clearance. The configuration with partial shrouds shows higher efficiency and energy coefficients compared to other configuration. Krain Hartmut (2002) observed the effect of unsteady diffuser flow in a transonic centrifugal compressor. Comparative study of unsteady flows in a transonic centrifugal compressor with vaneless and vane diffusers were observed by Curi Michael (2005).

\section{Experimental facility}

The present experimental investigations are carried on a low speed centrifugal compressor set up available in the Thermal Turbo Machines Laboratory, Departmental of Mechanical Engineering, Indian Institute of Technology Madras, and Thermal Engineering Laboratory, Mailam Engineering College.

The experimental set up shown in Fig.1 consists essentially a centrifugal impeller driven by a $5 \mathrm{~kW}$ D.C motor with a rated speed of $2000 \mathrm{rpm}$. The D.C motor is directly coupled to the shaft carrying the impeller. The main components of the compressor are suction duct, impeller, vane less diffuser formed by the front and rear walls of the casing and volute casing of circular cross section and a delivery duct with a throttle outlet and nozzle at the inlet.
Research article

CIndian Society for Education and Environment (iSee)
"Centrifugal compressor" http://www.indjst.org
Senthil \& Mohan Indian J.Sci.Technol. 
Vol.2 No. 7 (July 2009)

ISSN: 0974- 6846
Fig. 1. Schematic of centrifugal compressor setup

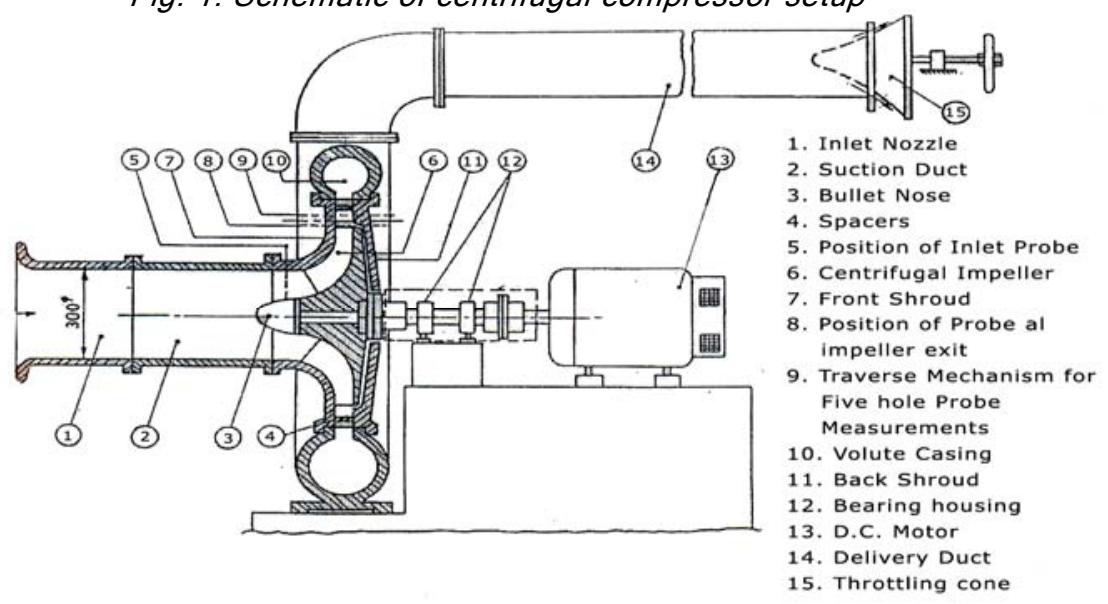

Blade angle at exit a) hub: $75^{\circ}$ b) mean: $90^{\circ}$ c) tip: $105^{\circ}$

All the angles are measured w.r.t. tangential direction.

Squealers

Squealers are used to improve performance of the compressor. They are made up of mild steel of $3 \mathrm{~mm}$ thickness. Squealers are welded on suction side of the blade, pressure side of the blade and both suction and pressure sides of the blade. The meridional view and blade-toblade view of the impeller with the squealers tips are shown in Fig.2-3.

Experimental programme

The objective of the present The major geometrical details of the impeller are given below:

Pressure rise $300 \mathrm{~mm}$ of WG

Volume flow rate $1.2 \mathrm{~m}^{3} / \mathrm{s}$ Speed of Rotation $2000 \mathrm{rpm}$

No. of blades of the impeller $: 16$ Inducer tip dia : $300 \mathrm{~mm}$

Fig. 2. Types of squealers

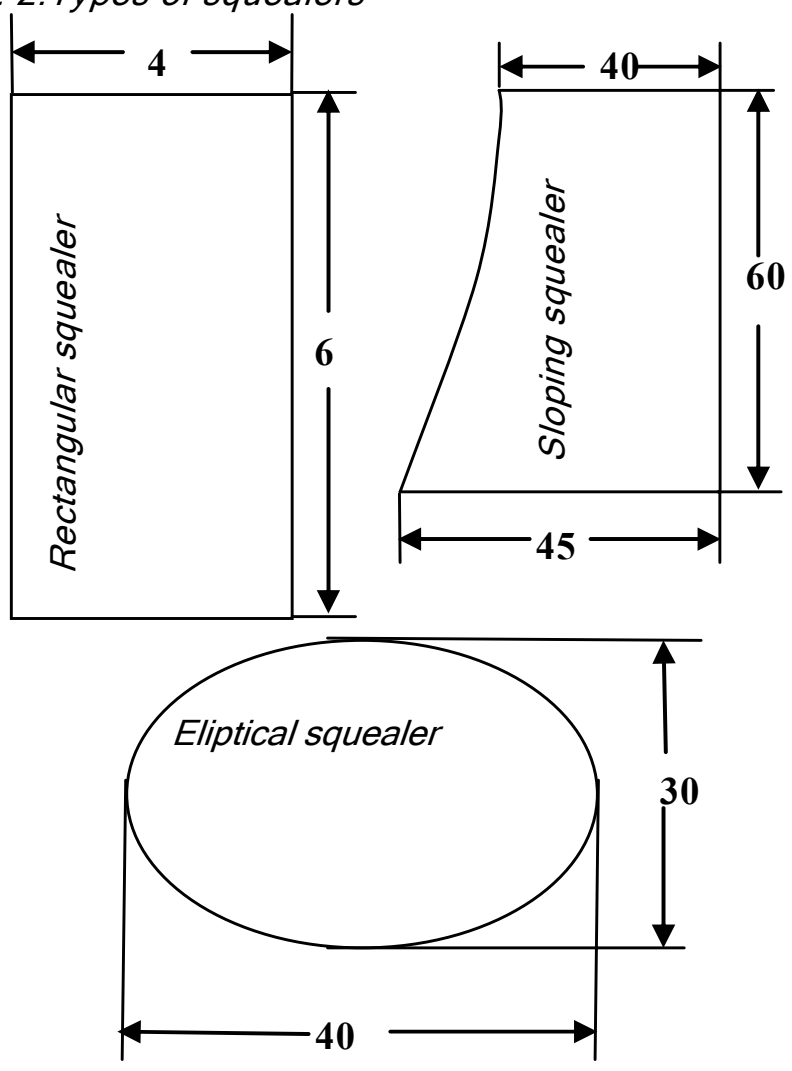

Inducer hub dia

$: 160 \mathrm{~mm}$

Impeller tip dia

: $500 \mathrm{~mm}$

Blade height at the exit

Blade angle at Inducer tip

$: 34.74 \mathrm{~mm}$

$: 35^{0}$

Blade angle at Inducer hub $\quad: 53^{\circ}$

Research article

CIndian Society for Education and Environment (iSee) investigation is to explore the possibility of using various types of squealer to improve the performance of centrifugal compressors. The present experimental programme consists of testing the centrifugal compressor with following types of squealers:

a) Rectangular squealer

b) Elliptical squealer

c) Sloping type squealer

Performance characteristics for rectangular squealer

The performance study of centrifugal compressor with rectangular squealer is carried out at constant speed of $2000 \mathrm{rpm}$ for the following tip configurations.

a) Rectangular squealer on suction side.ctangular squealer on pressure side.

Fig.2a. Types of squealers.

Squealer tip on pressure side
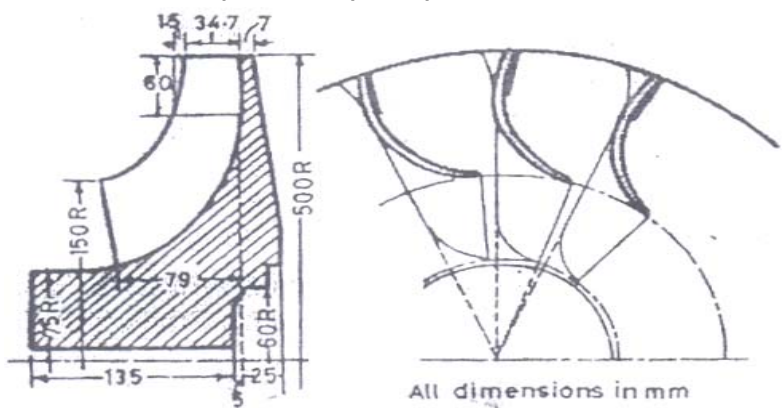

Squealer tip on suction side

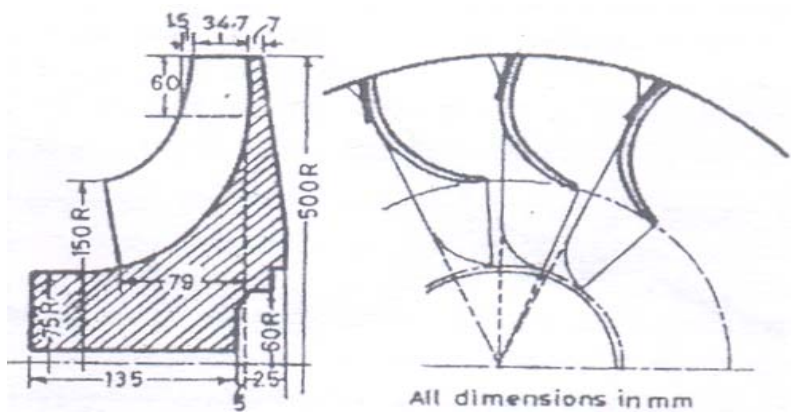

Senthil \& Mohan

"Centrifugal compressor" http://www.indjst.org
All dimensions in $\mathrm{mm}$ 
b) Rectangular squealer on both suction and pressure sides.

c) Solid tip by filling the space between rectangular squealers. Under steady state conditions, the inlet static pressure across the nozzle, the delivery static pressure across the delivery duct, the input field \& armature voltages and the input field \& armature currents are noted down. The speed of the compressor is maintained at 2000 rpm indicated by a non-contacting type tachometer. From these measurements, energy co-efficient and efficiency of the centrifugal compressor are computed and plotted against the flow coefficient. The performance tests are conducted for the above four configurations. Fig. 4 shows the performance characteristics in terms of energy co-efficient $\psi$ vs. flow co-efficient $\phi$. Fig. 5 shows the performance characteristics in terms of efficiency $\eta$ vs. flow coefficient $\phi$.

From the performance curves, it is found that pressure surface squealer tip configuration shows increased energy co-efficiency and efficiency of the compressor compared to other configurations. It is observed that the effect of suction side squealer tip on the energy co-efficient is comparable. In the high flow coefficient region, both configurations have nearly same energy co-efficient and efficiencies. In the lower flow coefficient region, configuration with pressure side squealer gives as much as $5 \%$ higher energy co-efficient, compared to that of suction side squealer. However, configuration with squealers on both suction and pressure sides gives lowest energy co-efficient. This is due to a large flow disturbance in the tip region for this configuration.

\section{Performance characteristics for elliptical squealer}

The performance study of centrifugal compressor with elliptical squealer is carried out at constant speed of $2000 \mathrm{rpm}$ for four configurations. Measurements are taken by following the above mentioned procedure. From these measurements energy co-efficient and efficiency of the centrifugal compressor are computed and plotted against the flow co-efficient. These curves are shown in Fig. 6- 7.

Performance characteristics for sloping type squealer

The performance study of centrifugal compressor with sloping type squealer is carried out at constant speed of $2000 \mathrm{rpm}$ for four configurations. Measurements are taken by following the above mentioned procedure. From these measurements energy co-efficient and
Vol.2 No. 7 (July 2009)

ISSN: 0974- 6846

efficiency of the centrifugal compressor are computed and plotted against the flow co-efficient. These curves are shown in Fig. 8-9.

Table 1 provides the comparison of rectangular, elliptical and sloping type squealer tips. It is concluded that sloping type squealer tip configuration gives more reasonable and beneficial performance when compared to other types of squealers.

The following formulae are used to calculate the flow parameters:

Flow Coefficients, $\phi$

The actual volume flow through the compressor is expressed as a non-dimensional parameter flow coefficient $\phi$, defined as the ratio of radial velocity to the peripheral velocity at the

impeller exit.

$\phi=\frac{V}{\pi d_{2} b_{2} U_{2}}=\frac{\pi d_{2} b_{2} c r_{2}}{\pi d_{2} b_{2} U_{2}}=\frac{c r_{2}}{U_{2}}$

where $\quad \mathrm{V}$ - volume flow rate

$\mathrm{d}_{2}$ - impeller tip diameter

$b_{2}$ - width at the impeller exit

$\mathrm{Cr}_{2}$ - radial velocity at the impeller exit

$U_{2}$ - peripheral velocity at the impeller exit

The actual volume flow rate is obtained from the

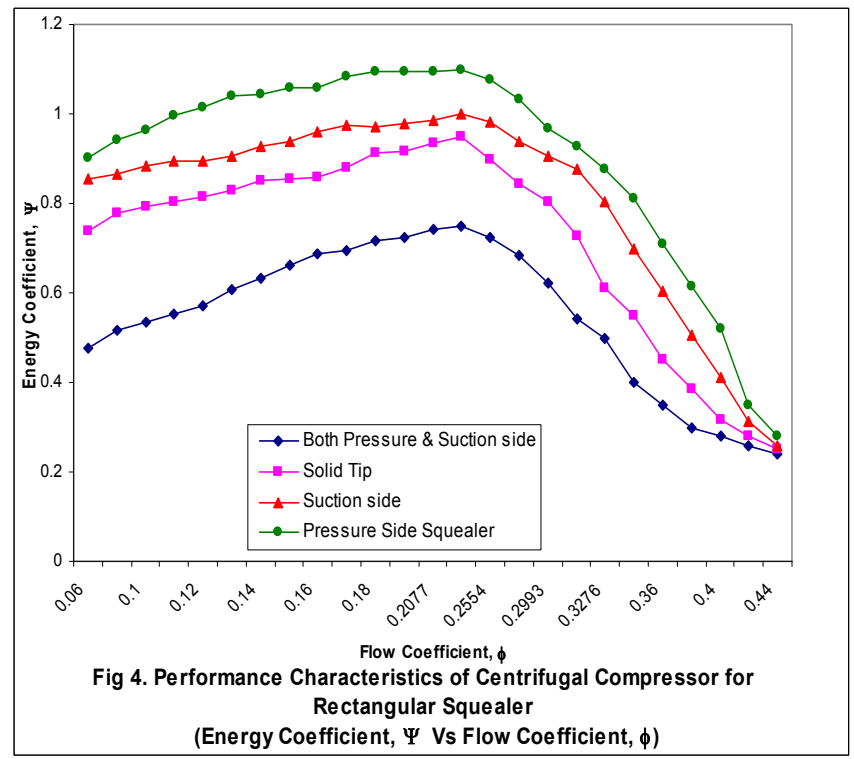


calibration curve of the inlet nozzle corresponding to the static pressure differential at the nozzle section. In the present investigation, the flow coefficients selected are:

$\phi_{\mathrm{d}}=0.28$ (near design) $\phi_{1}=0.18$ (below design) and $\phi_{\mathrm{h}}=0.34$ (above design)

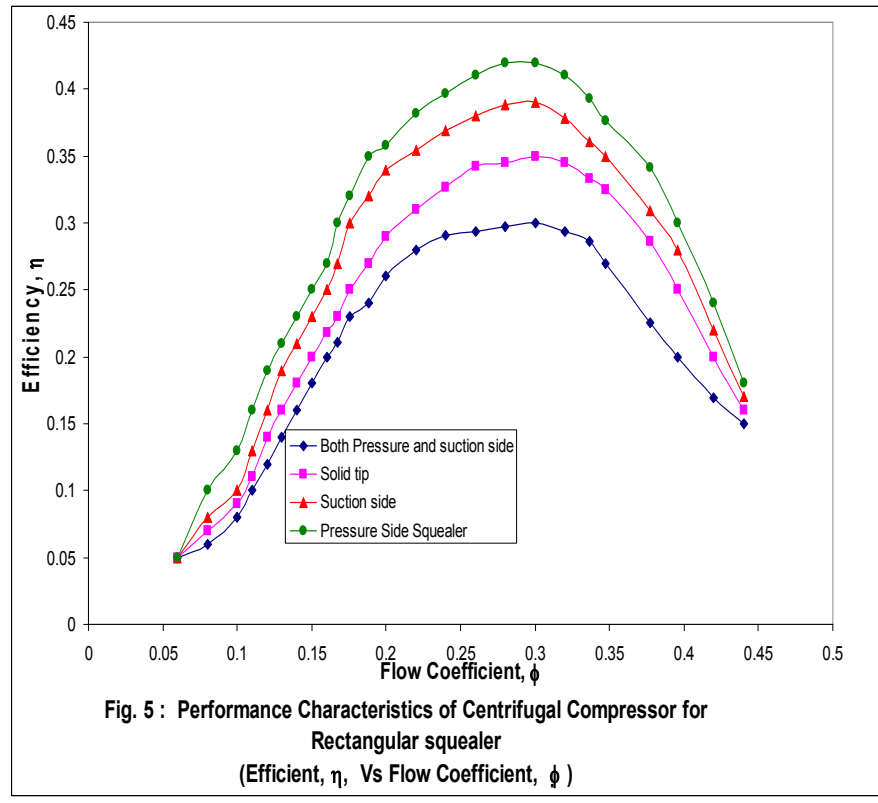

\section{Energy Ccoefficient, $\psi$}

The specific work $W$ for the centrifugal compressor is expressed non-dimensionally as the energy coefficient, $\psi$

$\psi=\frac{2 W}{U_{2}^{2}}$

where the specific work $W$ is obtained as the difference of specific total energy between inlet and exit of the impeller. For incompressible flow, the specific work is given by

$$
W=\frac{P_{D}-P_{s}}{\rho}+\frac{C_{D}^{2}-C_{S}^{2}}{2}+g \Delta z
$$

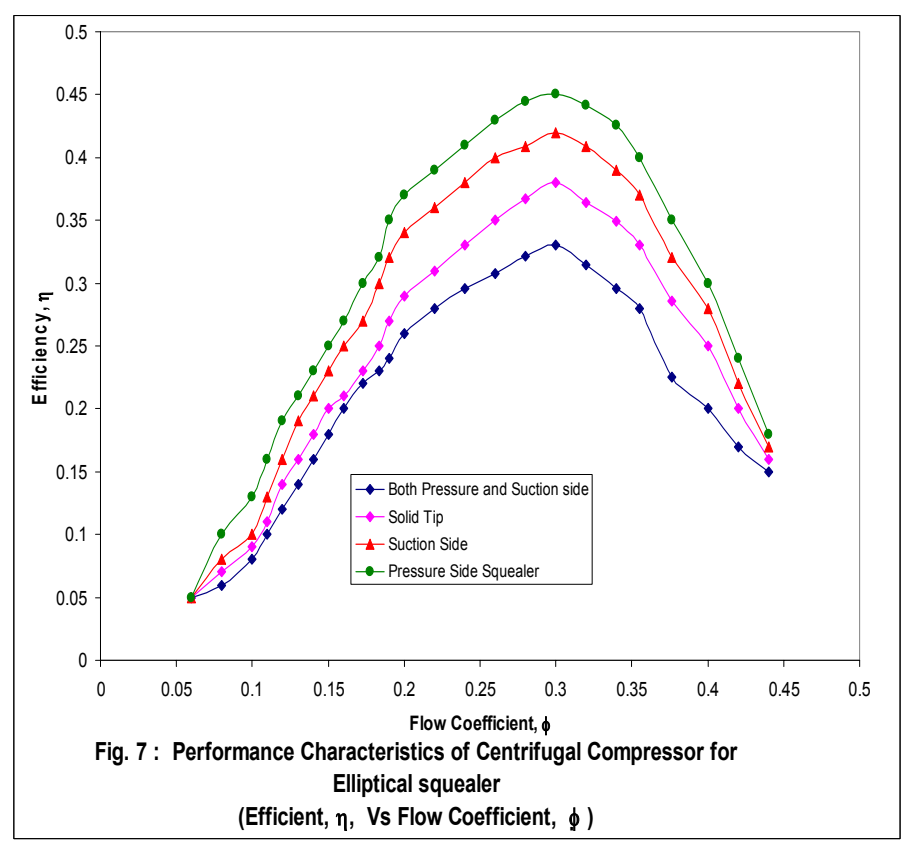

where $P_{d}$ and $P_{s}$ are the average static pressure measured at the exit and inlet sections and $C_{d}$ and $C_{s}$ are air velocities at the exit and inlet sections respectively. $\Delta Z$ is the geometric level difference between delivery and suction flanges and $\rho$ is the density of air. The density of the air is calculated from atmospheric pressure and temperature.

Efficiency, $\eta$

The efficiency is the ratio of fluid power output to the coupling power input of the compressor.
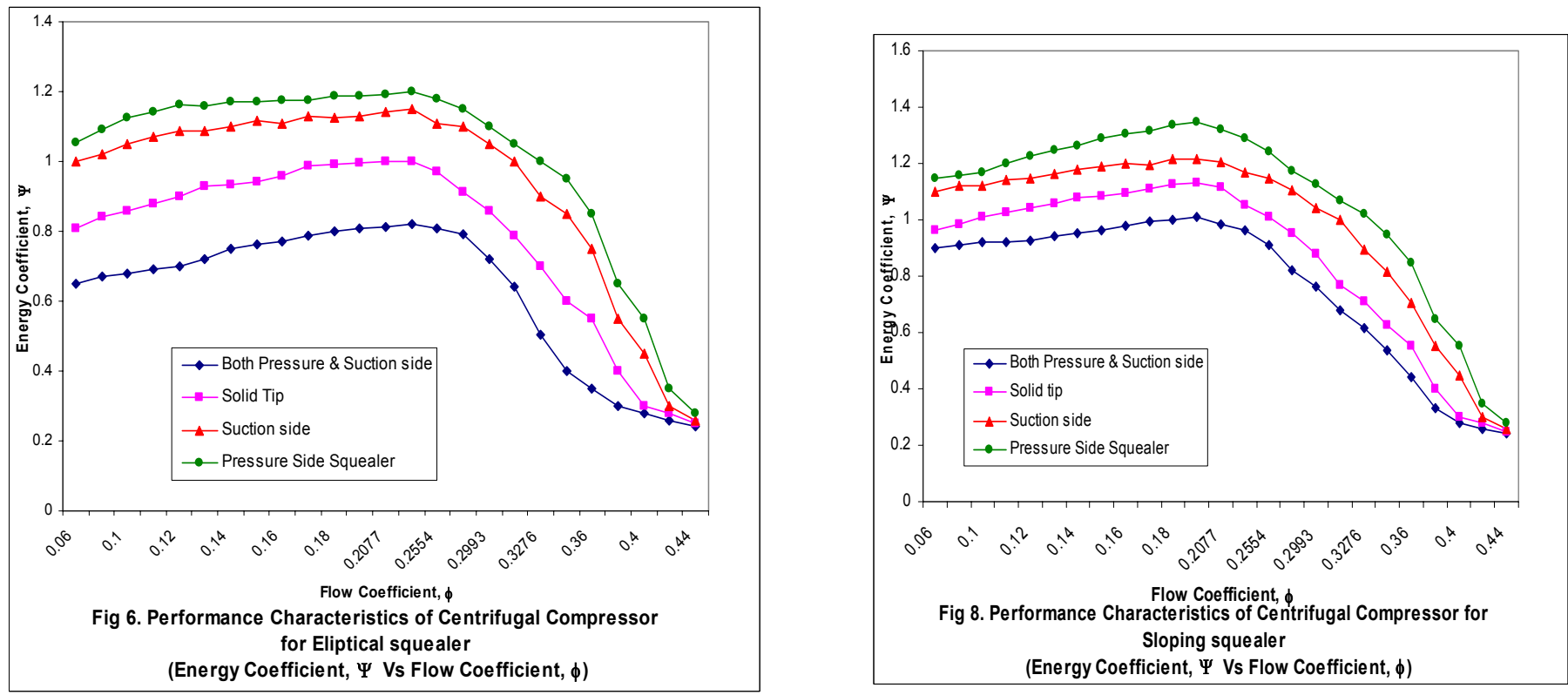

Research article

CIndian Society for Education and Environment (iSee)
"Centrifugal compressor" http://www.indjst.org
Senthil \& Mohan Indian J.Sci.Technol. 
$\eta=\frac{N_{\text {eff }}}{N_{c}}=\frac{\rho V W}{N_{c}}$

$\mathrm{N}_{\text {eff }}=$ Fluid power, Watts

$\rho=$ Density of air, $\mathrm{kg} / \mathrm{m}^{3}$

$\mathrm{V}=$ Volume flow rate, $\mathrm{m}^{3} / \mathrm{s}$

$\mathrm{W}=$ Specific work, $\mathrm{m}^{2} / \mathrm{s}^{2}$

$N_{c}=$ Coupling power,watts $=\eta_{m}\left[V_{a} l_{a}+V_{f} I_{f}\right]$

$\eta_{\mathrm{c}}=$ Efficiency of the motor

$\mathrm{V}_{\mathrm{a}}=$ Armature voltage, Volt

$\mathrm{I}_{\mathrm{a}}=$ Armature current, Ampere

$V_{f}=$ Field Voltage, Volt

$I_{f}=$ Field current, Ampere

\section{Conclusions}

1. Sloping squealer tip configuration gives more reasonable and beneficial performance when compared to other types of squealers.

2. Pressure side squealer tip has beneficial effects in increasing energy co-efficient and efficiency of the centrifugal compressor for rectangular, elliptical and sloping type squealers.

3. Suction side squealer tip has comparable beneficial effect on the energy co-efficient and efficiency.

\section{References}

1. Ameri AA, Rigby DL and Steinthorsson E (1998) Effect of Squealer Tip on Rotor Heat Transfer and efficiency. Trans. ASME J1. Turbomachinery. 120, 753-759.

2. Azad, Gm., Han SJ-C and Boyle RJ (2000) Heat Transfer and flow on the Squealer tip of a gas turbine blade. Trans. ASMEJ1. Turbomachinery. 122, 725-732.

3. Biba Yuri (2004) Inverse design of centrifugal compressor stages using a meanline approach. Intl. J. Rotating Machinery. 135, 146-157.

4. Cui Michael M (2005) Comparative study of unsteady flows in a transonic centrifugal compressor with vaneless and vaned diffusers. Intl. J. Rotating Machinery. 187, 86-98.

5. Heyes FJG, Hodson HP and Dailey GM (1992) The effect of blade tip geometry on the tip leakage flow in axial turbine cascade. Trans. ASME $J 1$. Turbomachinery. 114, 643-651.

6. Krain H (1987) Experimental and theoretical analysis of centrifugal impeller flow. Proc. Inst. Mech. Engrs. Conf. Paper C270/87, 199-209.

7. Krain Harmut (2002) Unsteady diffuser flow in a transonic centrifugal compressor. Intl. J.Rotating Machinery. 86, 112-123.

8. Pampreen (1973) Tip leakage flow in Axial and centrifugal compressors. Trans. ASME J1. Turbomachinery. 113, 252-261.

9. Senoo and Ishida (1987) Deterioration of compressor performance due to tip clearance of
Vol.2 No. 7 (July 2009)

ISSN: 0974- 6846

centrifugal impellers. Trans. ASME J1. Turbomachinery. 109, 55-61.

10. Senoo (1981) on the pressure losses due to the tip clearance of centrifugal blower. Trans. ASME J1. Engg. for Power. 103, 271-278.

11. Shridhara (2001) Review: recent investigations on tip clearance effects in centrifugal compressors. Int. J1 Jet Engines \& Turbomachines. 42, 309315.

\section{Nomenclature}

$b_{2}$ Width at the impeller exit

$\mathrm{d}_{2}$ Impeller tip diameter

$\mathrm{C}_{\mathrm{d}} \quad$ Air velocity at exit

$\mathrm{C}_{\mathrm{r} 2}$ Radial velocity at the impeller exit

$\mathrm{C}_{\mathrm{s}}$ Air Velocity at inlet

$\mathrm{I}_{\mathrm{A}}$ Armature current, Amps

$I_{F}$ Field current, Amps

$\mathrm{N}_{c} \quad$ Coupling power, Watts $=\mathrm{A}_{m}\left[\mathrm{~V}_{\mathrm{a}} \mathrm{l}_{\mathrm{A}}+\mathrm{V}_{\mathrm{f}} \mathrm{l}_{\mathrm{f}}\right]$

$\mathrm{N}_{\text {eff }}$ Fluid power, Watts

$\mathrm{P}_{\mathrm{d}} \quad$ Average static pressure at exit

$\mathrm{P}_{\mathrm{o} 2}$ Total pressure

$\mathrm{P}_{\mathrm{s}} \quad$ Average static pressure at inlet

$\mathrm{P}_{\mathrm{s} 2} \quad$ Static pressure

$P_{\text {ws }}$ Static pressure on the diffuser hub or shroud wall

$\mathrm{U}_{2} \quad$ Peripheral velocity at the impeller exit

$\checkmark$ Volume flow rate, $\mathrm{m}^{3} / \mathrm{s}$

$V_{A} \quad$ Armature voltage, volts

$\mathrm{V}_{\mathrm{F}} \quad$ Field current, Volts

$\mathrm{W} \quad$ Specific work $=\frac{P_{d}-P_{s}}{\rho}+\frac{C_{d}^{2}-C_{s}^{2}}{2}+g \Delta Z$

$\Delta Z \quad$ Geometric level difference between delivery and suction flanges

Table 1. Comparison of rectangular, elliptical and sloping type squealer tips

\begin{tabular}{|l|l|l|l|l|l|l|}
\hline \multirow{2}{*}{$\begin{array}{c}\text { Squealer } \\
\text { Configurations }\end{array}$} & \multicolumn{3}{|c|}{ Energy coefficient } & \multicolumn{3}{c|}{ Efficiency } \\
\cline { 2 - 7 } & RS & ES & SS & RS & ES & SS \\
\hline Pressure side & 1.1 & 1.2 & 1.3 & 0.42 & 0.45 & 0.48 \\
\hline Suction side & 1.0 & 1.15 & 1.2 & 0.39 & 0.42 & 0.44 \\
\hline $\begin{array}{l}\text { Both pressure } \\
\text { and suction } \\
\text { side }\end{array}$ & 0.75 & 0.82 & 1.0 & 0.30 & 0.33 & 0.35 \\
\hline $\begin{array}{l}\text { Solid tip by } \\
\text { filling the } \\
\text { space between } \\
\text { squealers }\end{array}$ & 0.95 & 1.0 & 1.1 & 0.35 & 0.38 & 0.4 \\
\hline \multicolumn{3}{|c|}{$R S$ - Rectangular squealer; ES - Elliptical squealer; } \\
\hline \multicolumn{3}{|c|}{ SS - Sloping type squealer tips. } \\
\hline
\end{tabular}

Research article

CIndian Society for Education and Environment (iSee)
"Centrifugal compressor" http://www.indjst.org
Senthil \& Mohan Indian J.Sci.Technol. 